\title{
Left Paraduodenal Hernia
} Successfully Treated with Laparoscopic Surgery: A Case Report

\author{
Tuyoshi Shoji Raisuke Nishiyama Koji Oba \\ Masaki Azuma \\ Department of Surgery, Haibara General Hospital, Makinohara City, Shizuoka, \\ Japan
}

\section{Key Words}

Paraduodenal hernia - Laparoscopic surgery · MRI

\begin{abstract}
A 60-year-old Japanese man was referred for examination of abdominal pain. Abdominal MRI exactly demonstrated paraduodenal hernia. Propylthiouracil was administered until the patient became euthyroid, because Graves' disease was detected during the subsequent general examinations. Laparoscopic repair was then carried out. The sac collar, which had a diameter of about $30 \mathrm{~mm}$, was located lateral to the ascending portion of the duodenum. Bowel incarcerated in the hernia sac was reduced and the hernia orifice closed. The postoperative course was good, and the patient was discharged 7 days after surgery. The diagnosis by MRI has made possible laparoscopic surgery for paraduodenal hernia.
\end{abstract}

\section{Introduction}

Paraduodenal hernias are rare causes of acute abdomen and are frequently complicated by volvulus and ischemia. Abdominal computed tomography (CT) currently plays an important role in the evaluation and management of patients with paraduodenal hernias [1-9]. Furthermore, we present the MRI image, because the symptoms of our patient resolved spontaneously. MRI images of paraduodenal hernia are very expensive because they only describe sagittal findings.

We herein describe a patient who was preoperatively diagnosed with left paraduodenal hernia and underwent successful laparoscopic surgery. 


\section{Case Report}

A 60-year-old Japanese man was admitted to our hospital with abdominal pain. Physical examination demonstrated a soft mass in the left upper abdomen. Laboratory investigations included normal carcinoembryonic antigen and thyrotropin of $1.15 \mathrm{mU} / \mathrm{l}$.

CT showed a homogenous, smooth mass on the left side of the abdomen (fig. 1). MRI demonstrated sagittal findings (fig. 2). MRI revealed the incarcerated small bowel between stomach and kidney. Barium enema confirmed that the small bowel formed jejunal loops behind the stomach (fig. 3 ).

Contrast study can be helpful in localizing the specific site of the obstruction. The pain had sometimes been precipitated by food 10 years previously and hyperthyroidism was diagnosed as Graves' disease. Thionamide drug (propylthiouracil) was the initial therapy in this case. Propylthiouracil was given for 6 weeks until the patient became euthyroid; then surgery for paraduodenal hernia was performed. One $10 \mathrm{~mm}$ port and three $5 \mathrm{~mm}$ ports were used. The surgical duration was $120 \mathrm{~min}$, and total blood loss was $50 \mathrm{ml}$. A hernial orifice about $3 \mathrm{~cm}$ in diameter was observed under the ligament of Treitz (fig. 4). Approximately $30 \mathrm{~cm}$ of jejunum was within the hernial sac. Herniography was performed after reduction of the jejunum (fig. 5). The hernial orifice was closed with non-absorbable suture. The postoperative course was uneventful.

\section{Discussion}

Paraduodenal hernias are also called congenital mesocolial hernia. The etiology may involve bowel malrotation during the embryonal period and maladhesion between the mesocolon and retroperitoneum. Paraduodenal hernias are the most common internal hernias, accounting for $53 \%$ of cases [10]. In Japan, $68 \%$ were on the left and $32 \%$ on the right, $70 \%$ of these cases were male and $30 \%$ female [11].

Paraduodenal hernia can be asymptomatic and diagnosed incidentally at laparotomy $[11,12]$. Some patients have vague abdominal complaints and subclinical symptoms related to long-term intermittent or partial obstruction $[1,6,8,9,13,14]$, while others present with acute closed-loop obstruction or intestinal ischemia $[2-5,7,15,16]$. In our case, the patient was admitted with a ten-year history of episodic colicky peristaltic abdominal pains.

The difficulty in clinically diagnosing internal hernia means that imaging studies could play an important role if accurate and reliable signs can be determined $[5-9,16,17]$. Small bowel follow-through films taken with barium showed that the jejunum occupied the upper-right part of the abdomen.

CT findings for left-sided paraduodenal hernia show a characteristic appearance of a cluster of dilated small-bowel loops seemingly encased in a sac and lying between the pancreatic body and the stomach to the left of the ligament of Treitz [1-9, 13, 18]. In the case of left paraduodenal hernia, IMV were usually located in the upward and anterior displacement of the hernia sac. In our case, encapsulated small bowel loop formation was located between pancreas and stomach.

In addition, MRI findings of paraduodenal hernia were not previously reported. In our case, the symptoms were subacute; therefore MRI was obtained and played an important role in providing sagittal findings. This image made possible exact and speedy diagnosis of paraduodenal hernia. Thus, it was possible to diagnose left paraduodenal hernia preoperatively in an asymptomatic or subacute symptom case.

Surgical management requires opening of the sac and reduction of the herniated small bowel, with resection as needed of the nonviable segment $[4,15]$. Ladd's procedure or 


\begin{tabular}{c|l|l|l}
$\begin{array}{c}\text { CaseReportsin } \\
\text { Gastroenterology }\end{array}$ & $\begin{array}{l}\text { Case Rep Gastroenterol 2007;1:71-76 } \\
\text { D0I: 10.1159/000107595 }\end{array}$ & Published online: August 24, 2007 & $\begin{array}{l}\text { 2007 S. Karger AG, Basel } \\
\text { ISSN 1662-0631 } \\
\text { www.karger.com/crg }\end{array}$ \\
\hline
\end{tabular}

simple closure is then performed $[1,6,12,13,16]$. In our case, Ladd's procedure was not performed because there were no rotational abnormalities.

Laparoscopic management of a left paraduodenal hernia has been described $[3,6,9]$. In our case, there did not appear to be any bowel necrosis or severe dilatation. Therefore, laparoscopic surgery was indicated. MRI is useful for diagnosis on the case of paraduodenal hernia and it makes possible the use of laparoscopic surgery.

Fig. 1. CT examination of the abdomen revealed a smooth surface mass on the left side of the abdomen.

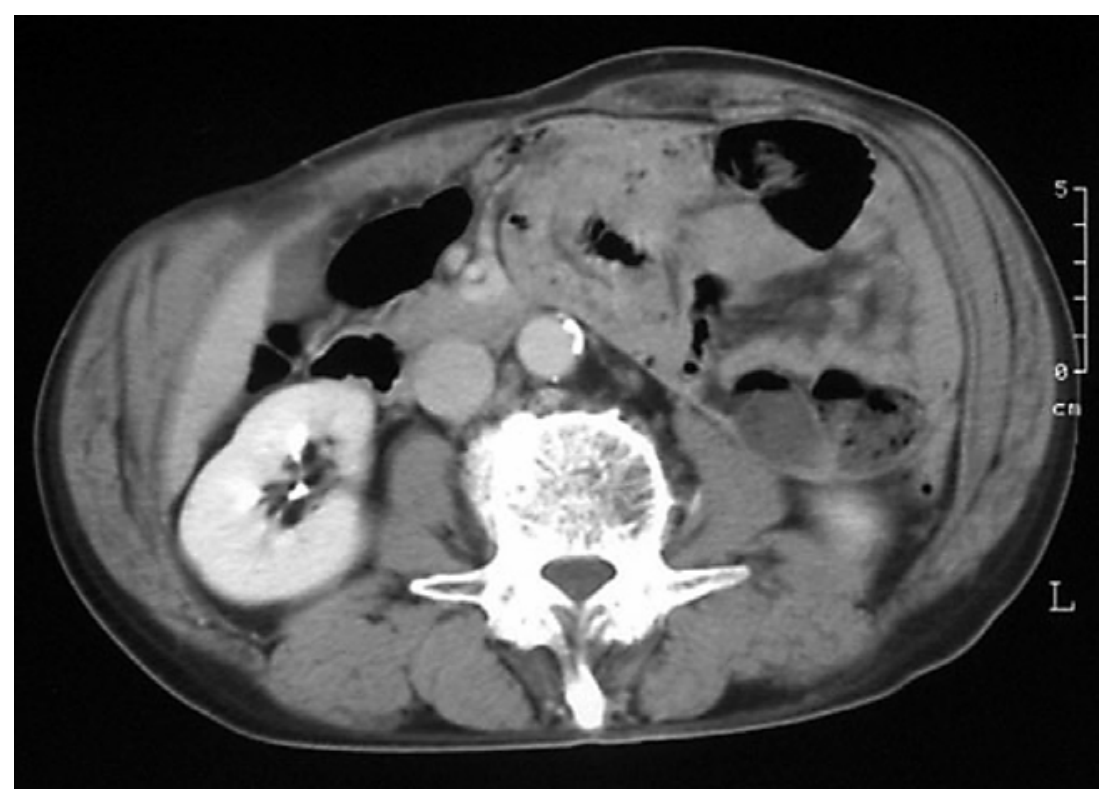


CaseReportsin |Case Rep Gastroenterol 2007;1:71-76 Gastroenterology DOI: $10.1159 / 000107595$

Fig. 2. MRI revealed a mass between stomach and kidney.

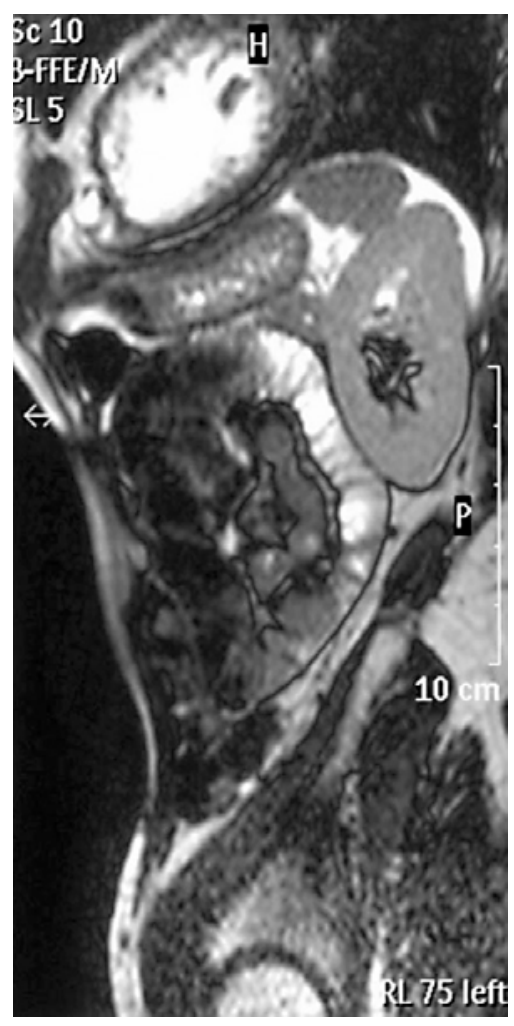

Fig. 3. Barium enema showed the jejunal loops behind the stomach.

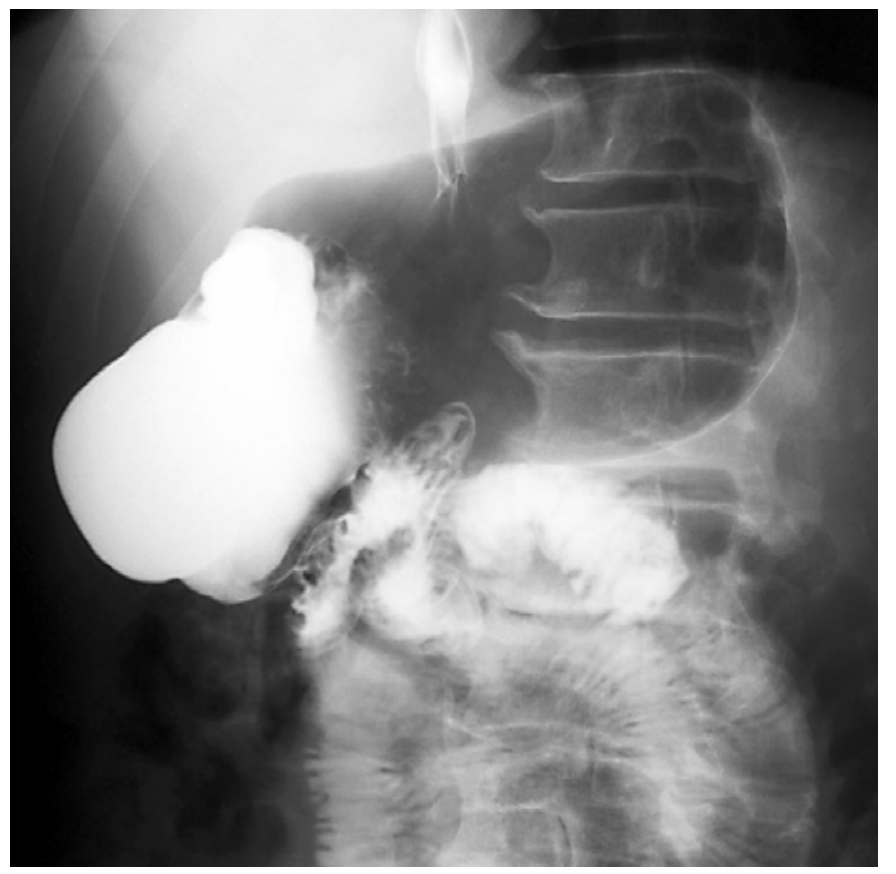


CaseReportsin | Case Rep Gastroenterol 2007;1:71-76 Gastroenterology

Fig. 4. A hernia orifice was observed under the ligament of Treitz.

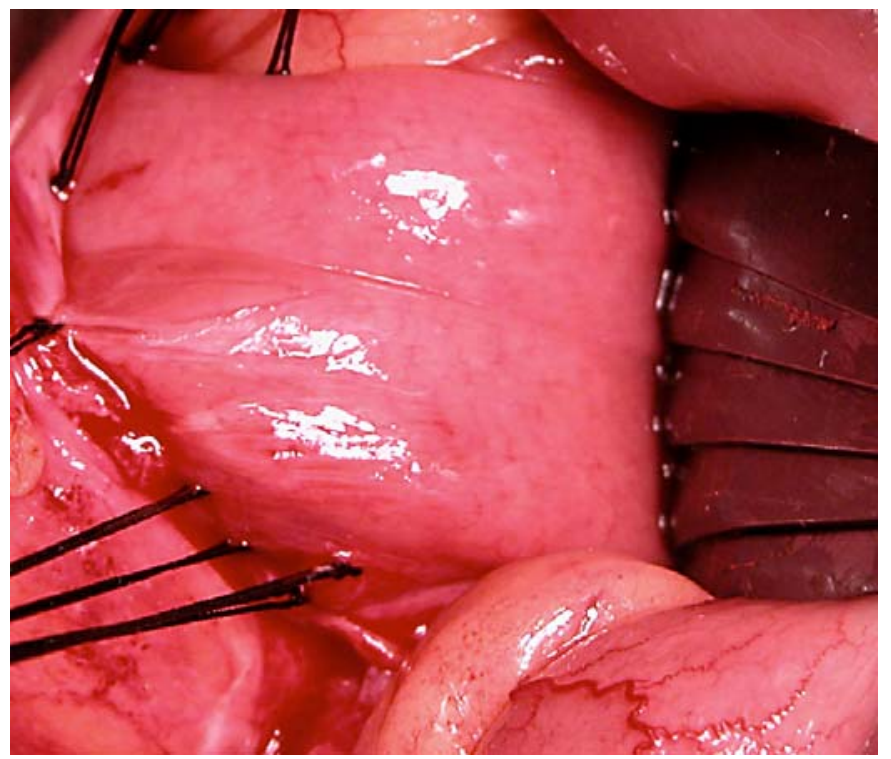

Fig. 5. Herniography after reduction of jejunum.

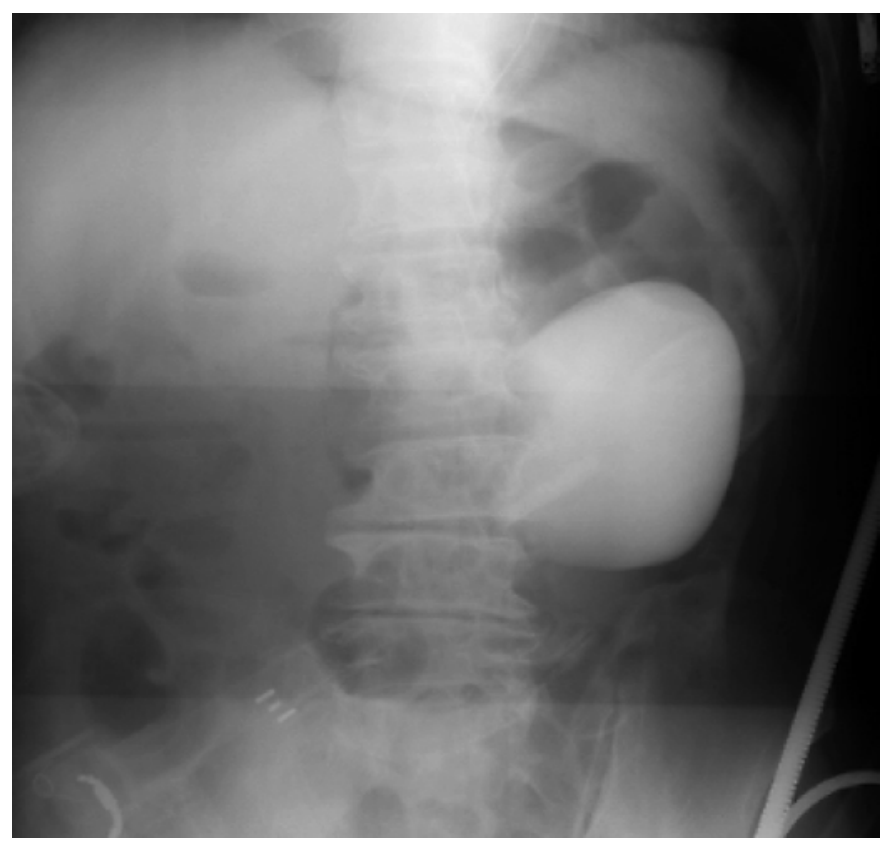




\section{References}

1 Vyas FL, Jesudason MR, Mathai V, Jesudason SR: Left paraduodenal hernia: an uncommon cause of chronic abdominal pain. Trop Gastroenterol 2004;25:189190.

-2 Catalano OA, Bencivenga A, Abbate M, Tomei E, Napolitano M, Vanzulli A: Internal hernia with volvulus and intussusception: case report. Abdom Imaging 2004;29:164-165.

-3 Osadchy A, Weisenberg N, Wiener Y, Shapiro-Feinberg M, Zissin R: Small bowel obstruction related to left-side paraduodenal hernia: CT findings. Abdom Imaging 2005;30:53-55.

-4 Antao B, Hamill J, Samuel M, Hiorns M, Pierro A: Herniation through the foramen of Winslow presenting as obstructive jaundice. Pediatr Surg Int 2005;21:560-562.

5 Tainaka T, Ikegami R, Watanabe Y: Left paraduodenal hernia leading to proteinlosing enteropathy in childhood. J Pediatr Surg 2005;40:E21-E23.

6 Fukunaga M, Kidokoro A, Iba T, Sugiyama K, Fukunaga T, Nagakari K, et al: Laparoscopic surgery for left paraduodenal hernia. J Laparoendosc Adv Surg Tech 2004;14:111-114.

7 Anderson CD, Eliason J, Roberts JR, Sharp KW: Bilateral diaphragmatic agenesis in an adult complicated by a paraduodenal hernia. Am Surg 2003;69:523-525.

8 Rollins MD, Glasgow RE: Left paraduodenal hernia. J Am Coll Surg 2004;198:492-493.

9 Antedomenico E, Singh NN, Zagorski SM, Dwyer K, Chung MH: Laparoscopic repair of a right paraduodenal hernia. Surg Endosc 2004;18:165-166.

10 Berardi RS, Iowa DM: Paraduodenal hernias. Surg Gynecol Obstet 1981;152:99_ 110.

11 Kurachi K, Nakamura T, Hayashi T, Asai Y, Kashiwabara T, Nakajima A, et al: Left paraduodenal hernia in an adult complicated by ascending colon cancer: A case report. World J Gastroenterol 2006;12:1795-1797.

12 Brunner WC, Sierra R, Dunne JB, Simmang CL, Scott DJ: Incidental paraduodenal hernia found during laparoscopic colectomy. Hernia 2004;8:268270.

13 Patti R, Arcara M, Davi V, Dimarco V, Leo P, Divita G: Paraduodenal hernia: an uncommon cause of recurrent abdominal pain. G Chir 2004;25:183-186.

14 Tong RSK, Sengupta S, Tjandra JJ: Left paraduodenal hernia: Case report and review of the literature. ANZ J Surg 2002;72:69-71.

15 Ramachandran P, Sridharan S: Strangulated left paraduodenal hernia in an infant. Pediatr Surg Int 2003;19:120-121.

16 Patterson JA, Tadros EG, Wilkinson AJ: An unusual case of left paraduodenal hernia. Int J Clin Pract 2001;55:649.

17 Parsons PB: Paraduodenal hernias. Am J Roentgenol Radium Ther Nucl Med 1953;69:563-589.

18 Blachar A, Federal MP: Internal hernia: an increasingly common cause of small bowel obstruction. Semin Ultrasound CT MR 2002;23:174-183. 